\title{
Violation of Aseptic practices in Operation Theater
}

\begin{abstract}
${ }^{(1)}$ Fazilat U1 Noor, ${ }^{(2)}$ Sana Sehar, ${ }^{(3)}$ Muhammad Afzal, ${ }^{(4)}$ Prof. Dr. Syed Amir Gillani Lahore School of Nursing, The University of Lahore, Lahore, Pakistan

Abstract

Patient wellbeing has become a health policy need the world wide. Recognizing that 'to blunder is human' has prompted endeavors to plan frameworks and decides that point of confinement the limit with respect to singular prudence and subsequently diminish clinical mistakes. Surgical colleague's practices have significance with respect to the nature of care among the patient whose experience any of surgery. Shockingly it is seen that the surgical group didn't rehearse well and furthermore didn't pursue the standards, for example, legitimate scouring, wearing careful gloves and blended utilization of sterile and unsterile instruments. So in the lieu of these malrehearses nature of care may bargain and furthermore significant reason for careful site disease? In results the dismalness and death rate may increment. The objective of asepsis and aseptic method is to avoid the exchange of microorganisms into the careful injury. Counteracting careful site tainting requires the endeavors of all prepared careful colleagues to utilize their insight and involvement with aseptic practices to give their patients ideal care bringing about positive careful results. Then again to switch the careful group towards the appropriate practices, it is have to give legitimate assets (place, person and money), preparing for surgical group and furthermore diminish the outstanding task at hand.
\end{abstract}

Keywords: Aseptic practices, Operation Theater

DOI: $10.7176 / \mathrm{JHMN} / 68-13$

Publication date: November $30^{\text {th }} 2019$

\section{Introduction}

Patient wellbeing has become a health policy need the world wide. Recognizing that 'to blunder is human' has prompted endeavors to plan frameworks and decides that point of confinement the limit with respect to singular prudence and subsequently diminish clinical mistakes. Also, extraordinary accentuation is being set on the need to destroy societies of fault, which are accepted to debilitate clinicians from revealing mistakes, and to build up a 'safety culture', which supports receptiveness and trustworthiness.

These endeavors are supported by subjective mental clarifications of the way person's procedure data, for example, as unexpected workload, economical failure, and poor performance, which drive them to make mistakes of judgment. This paper looks at the infringement of activity theater administers in medical hospital by doctors, managers and nurses to the usage of rules with regards to patient safety.

Anticipating surgical site infection in the operating room is the essential objective of the surgical group, and all exercises performed by the group bolster this objective. A portion of these exercises incorporate understanding hazard appraisal, ecological cleaning, cleansing and disinfection of instrumentation, tolerant anti-toxin prophylaxis, and the utilization of standard safety measures. In any case, operating room exercises relating to asepsis and aseptic practices have the best immediate effect upon the careful group in diminishing the patient's hazard to surgical site contamination (Osman, 2000).

Violations are intentional deviations from standard technique. The standard response is to endeavor to dispense with them and censure those concerned. In any case, the circumstance isn't that straightforward. Right off the bat, infringement incomprehensibly might be markers of significant levels of wellbeing since they need requirements and guards to exist. They may even turn out to be more continuous than mistakes in ultra safe frameworks. Furthermore, infringement have both positive and negative angles (Adams, Korniewicz, \& El-Masri, 2011).

From one perspective they happen every now and again, increment framework execution and individual fulfillment, are for the most part restricted to rehearses with constrained wellbeing results, and along these lines are regularly endured or even energized by the chain of command (Amalberti, Vincent, Auroy, \& de Saint Maurice, 2006).

The standards of aseptic strategy assume an imperative job in achieving the objective of asepsis in the operating room condition. It is the obligation of each surgical staff part to comprehend the significance of these standards 
and to consolidate them into their ordinary practice. The standards of aseptic strategy incorporate the accompanying standards.

The surgical team is made up of sterile and nonsterile members. Sterile members or "scrubbed" personnel work directly in the surgical field while the nonsterile members work in the periphery of the sterile surgical field. All surgical team members wear scrub attire. In addition to scrub attire, scrubbed persons must wear a sterile surgical gown, mask, and gloves within the sterile field to establish bacterial barriers. These barriers protect the patient from the transmission of microorganisms from the surgical team (Owolabi, 2015).

When the scrubbed individual wears the clean surgical outfit, the outfit's sterility is restricted to the gown portions legitimately saw by the cleaned individual. These sterile zones incorporate the outfit front, from chest to the sterile field level, and the sleeves from two creeps over the elbow to the sleeve. The cleaned faculty consistently play out a careful hand scour preceding wearing their clean careful outfit and gloves (Danjuma, Babatunde, Taiwo, \& Micheal, 2016).

Sterile surgical drapes establish an aseptic barrier minimizing the passage of microorganisms from nonsterile to sterile areas. Sterile drapes should be placed on the patient, furniture, and equipment to be included in the sterile field, leaving only the incision site exposed. During the draping process, only scrubbed personnel should handle sterile drapes. The drapes should be held higher than the operating room bed with the patient draped from the prepped incision site out to the periphery. Once the sterile drape is positioned, it should not be moved or rearranged

Sterile surgical drapes hangings set up an aseptic hindrance limiting the section of microorganisms from nonsterile to sterile zones. Sterile window hangings ought to be put on the patient, furnishings, and hardware to be remembered for the sterile field, leaving just the entry point site uncovered. During the hanging procedure, just cleaned work force should deal with sterile window hangings. The window hangings ought to be held higher than the working room bed with the patient hung from the prepared entry point site out to the outskirts. When the sterile wrap is situated, it ought not be moved or revised (Onyegbule et al., 2015).

Under no circumstances should sterile and nonsterile items/areas be mixed since one contaminates the other. ${ }^{4}$ Sterilization provides the highest level of assurance that all instruments, sutures, fluids, supplies, and drapes are void of microorganisms. All sterile items should be dispensed to the sterile field by methods that preserve the integrity of the items and sterile field. ${ }^{1}$ Nonsterile personnel, usually the circulating nurse, must use good judgment when dispensing sterile items onto the sterile field either by presenting them directly to the scrubbed person or placing them securely on the sterile field (Agaja, 2010).

It is the responsibility of the operating room staff to monitor and maintain the sterile field. Sterility can never be absolutely guaranteed, but surgical team members should make every reasonable effort to reduce the likelihood of contamination and be vigilant to breaches in sterility. When a breach of sterility occurs, team members must take immediate and appropriate action to correct the break in technique to reduce further risk of contamination. Remember, if there is doubt regarding an item's sterility, consider it not sterile.

Since the patient is the focal point of the sterile field, scoured work force ought to stay near this territory without meandering around the room. This development can bring about pollution of the sterile field. Cleaned staff should move just from sterile regions to sterile territories. At the point when cleaned faculty change positions, they ought to keep up a sheltered good ways from one another and consistently pass each other by going consecutive or faceto-face. 2 This development lessens the danger of sullying by guaranteeing the scour people are passing either nonsterile to nonsterile or sterile to sterile (Eyarefe, 2016).

\section{Scenario}

Surgical colleague's practices have significance with respect to the nature of care among the patient whose experience any of surgery. Shockingly it is seen that the surgical group didn't rehearse well and furthermore didn't pursue the standards, for example, legitimate scouring, wearing careful gloves and blended utilization of sterile and unsterile instruments. So in the lieu of these mal-rehearses nature of care may bargain and furthermore significant reason for careful site disease? In results the dismalness and death rate may increment. 


\section{Conceptual framework}

Extraordinary infringement can prompt genuine risk or real hurt. This paper proposes a three stage model got from Rasmussen's hypothesis of movement to limits to clarify the component, by which the aberrance happens, balances out, relapses, or advances to hurt. The model recommends that infringements are unavoidable on the grounds that framework elements and deviances are markers of adjustment to this dynamicity. Infringement can't be wiped out yet they can be overseen. Arrangements are explicit to each progression of the model, with a blend of loosening up imperatives, expanding peer control (staff), and compelling hazardous people.

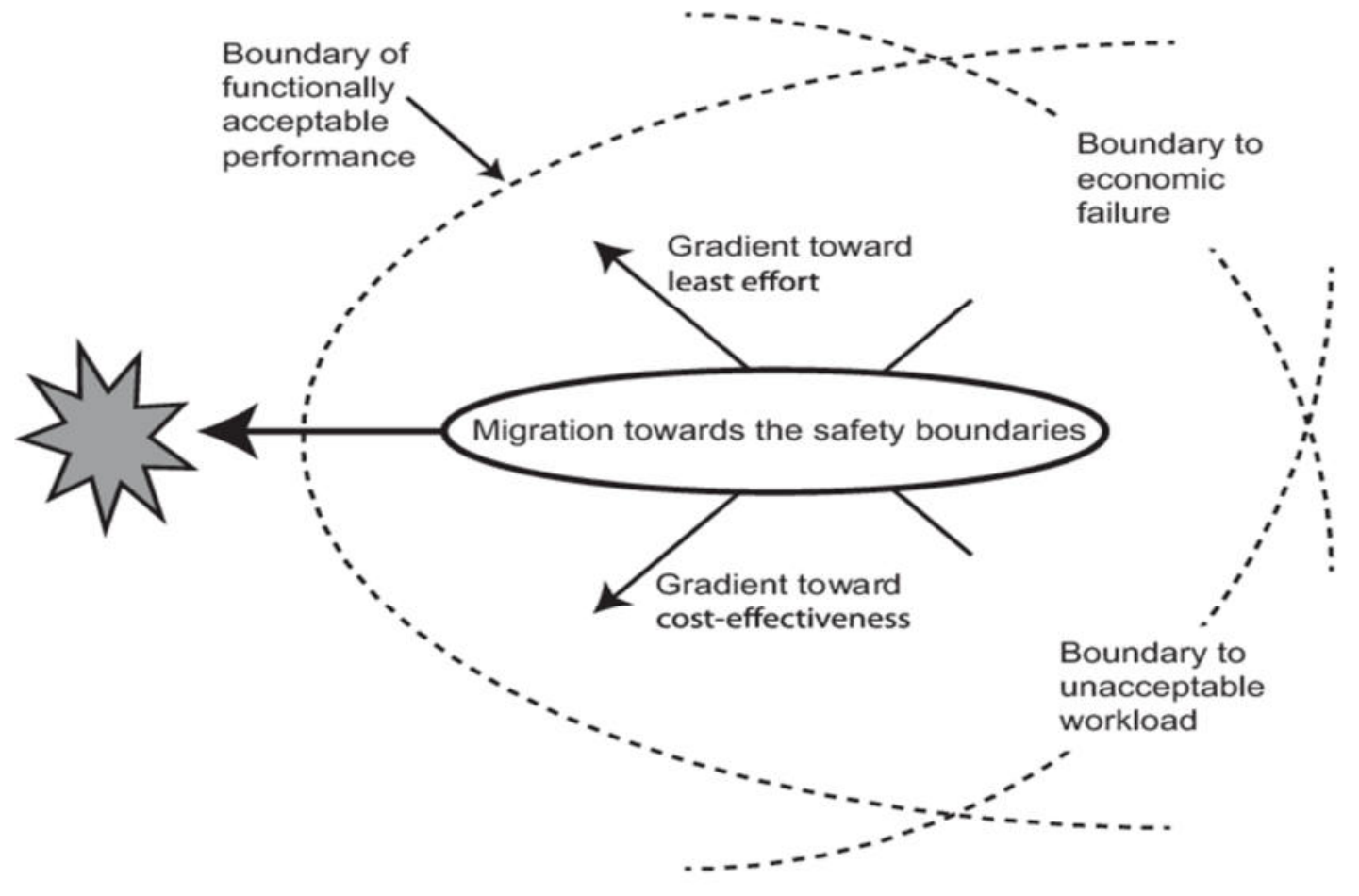

(Amalberti et al., 2006)

\section{Results}

All surgical colleagues must rehearse these standards of aseptic strategy to help forestall the exchange of microorganisms into the careful injury during the pre-employable period. It is the duty of the careful colleagues to build up a solid careful still, small voice, holding fast to the standards of asepsis and amending any ill-advised system saw in the working room. Notwithstanding the standards of asepsis, appropriate careful clothing assumes a significant job in the decrease of careful site diseases by diminishing the measure of hair and skin contaminants arriving at the sterile field.

The objective of asepsis and aseptic method is to avoid the exchange of microorganisms into the careful injury. Counteracting careful site tainting requires the endeavors of all prepared careful colleagues to utilize their insight and involvement with aseptic practices to give their patients ideal care bringing about positive careful results. Then again to switch the careful group towards the appropriate practices, it is have to give legitimate assets (place, person and money), preparing for surgical group and furthermore diminish the outstanding task at hand.

\section{Discussion}

Surgical site infection is one of the most well-known confusions following cesarean area, and has an occurrence of 3\%-15\%. It places physical and enthusiastic weights on the mother herself and a critical monetary weight on the social insurance framework. In addition, Surgical site disease is related with a maternal death pace of up to $3 \%$ (Zuarez-Easton, Zafran, Garmi, \& Salim, 2017). 
Aseptic method likewise incorporates rehearses performed proceeding and during a surgery to lessen post-usable disease. These incorporate, Hand washing, Surgical scour, Using careful hindrances, including clean careful curtains and appropriate individual defensive gear, including head covers, careful veils and outfits, gloves, and shoe covers. It is significant during understanding careful arrangement to keep up a sterile field (Allegranzi et al., 2016).

Hands are the most widely recognized vehicle for transmitting diseases, so it is important that social insurance laborers comprehend the significance of appropriate hand washing rehearses Hands are washed to expel noticeable soil and imperceptible irresistible material. They ought to be precisely fomented under running water and with an antimicrobial item for roughly 15 to 30 seconds. On the off chance that cleanser and water are not available, and if the hands are not noticeably grimy, the social insurance laborers may utilize a liquor hand rub (Barbadoro et al., 2014).

Appropriate gloving strategy likewise encourages the aseptic procedure. Gloves give an obstruction against possibly irresistible microorganisms that can be found in blood, other body liquids, and waste (Brewer et al., 2016).

Wearing appropriate defensive gears is a third method to help aseptic system. During surgeries, the two patients and medicinal services laborers are particularly in danger of presentation to conceivably irresistible microorganisms. Alongside different components of aseptic system, appropriate careful clothing diminishes the danger of post-method contaminations and during techniques. Careful clothing incorporates tops, gloves, veils, outfits, defensive eyewear, liquid verification covers, and footwear (Axt et al., 2013).

A fourth part of aseptic system is careful readiness. The warm, clammy conditions inside careful gloves give a perfect situation to the fast development of microorganisms, so scouring with germicides before starting surgeries will help forestall this quick development of microorganisms for a while and will decrease the danger of diseases to the patient if the gloves create openings, tears, or scratches during medical procedure (Güenaga, Matos, \& WilleJørgensen, 2011).

Antimicrobial specialists are utilized in the careful scour since they restrain the development and improvement of microorganisms and are ok for use on the skin. 3-5-minute careful scour with a germicide, (for example, chlorhexidine or an iodophor) and running water is suggested before a surgery (Ban et al., 2017).

Aseptic system to plan patients for medical procedure is shields against extreme control and shields customers from microorganisms in the earth. The skin is a fundamental wellspring of pathogens causing careful site disease. Preoperative skin arrangement utilizing appropriate aseptic methods with germ-free operators has been demonstrated to decrease the danger of careful site contamination (Hadiati, Hakimi, Nurdiati, da Silva Lopes, \& Ota, 2018).

Surgical site infections (SSI) represent $14 \%$ to $17 \%$ of all medical clinic obtained contaminations and $38 \%$ of nosocomial contaminations in careful patients. SSI stay a considerable reason for bleakness and demise, conceivably due to the bigger quantities of old careful patients or those with an assortment of ceaseless and immunocompromising conditions, and rise of anti-toxin safe microorganisms (Awad, 2012).

\section{References}

Adams, J., Korniewicz, D., \& El-Masri, M. (2011). A descriptive study exploring the principles of asepsis techniques among perioperative personnel during surgery. Canadian operating room nursing journal, 29(4), 6-8, 14-16, 21-14.

Agaja, S. B. (2010). Surgery: The Anchor of Life: Citeseer.

Allegranzi, B., Bischoff, P., de Jonge, S., Kubilay, N. Z., Zayed, B., Gomes, S. M., . . van Rijen, M. (2016). New WHO recommendations on preoperative measures for surgical site infection prevention: an evidence-based global perspective. The Lancet Infectious Diseases, 16(12), e276-e287.

Amalberti, R., Vincent, C., Auroy, Y., \& de Saint Maurice, G. (2006). Violations and migrations in health care: a framework for understanding and management. BMJ Quality \& Safety, 15(suppl 1), i66-i71.

Awad, S. S. (2012). Adherence to surgical care improvement project measures and post-operative surgical site infections. Surgical infections, 13(4), 234-237. 
Axt, J., Nthumba, P. M., Mwanzia, K., Hansen, E., Tarpley, M. J., Krishnaswami, S., . . Simeone, D. (2013). Commentary: the role of global surgery electives during residency training: relevance, realities, and regulations. Surgery, 153(3), 327-332.

Ban, K. A., Minei, J. P., Laronga, C., Harbrecht, B. G., Jensen, E. H., Fry, D. E., . . Duane, T. M. (2017). American College of Surgeons and Surgical Infection Society: surgical site infection guidelines, 2016 update. Journal of the American College of Surgeons, 224(1), 59-74.

Barbadoro, P., Martini, E., Savini, S., Marigliano, A., Ponzio, E., Prospero, E., \& D'Errico, M. (2014). In vivo comparative efficacy of three surgical hand preparation agents in reducing bacterial count. Journal of Hospital Infection, 86(1), 64-67.

Brewer, J. D., Gonzalez, A. B., Baum, C. L., Arpey, C. J., Roenigk, R. K., Otley, C. C., \& Erwin, P. J. (2016). Comparison of sterile vs nonsterile gloves in cutaneous surgery and common outpatient dental procedures: a systematic review and meta-analysis. JAMA dermatology, 152(9), 1008-1014.

Danjuma, A., Babatunde, A., Taiwo, O., \& Micheal, S. (2016). Rates and patterns of operating room hazards among Nigerian perioperative nurses. Journal of Perioperative \& Critical Intensive Care Nursing.

Eyarefe, O. D. (2016). Risk factors, prevention and control strategies for surgical site infections in veterinary practice in Nigeria-A review. Journal of Veterinary Medicine and Animal Health, 8(8), 72-82.

Güenaga, K. F., Matos, D., \& Wille-Jørgensen, P. (2011). Mechanical bowel preparation for elective colorectal surgery. Cochrane Database of Systematic Reviews(9).

Hadiati, D. R., Hakimi, M., Nurdiati, D. S., da Silva Lopes, K., \& Ota, E. (2018). Skin preparation for preventing infection following caesarean section. Cochrane Database of Systematic Reviews(10).

Onyegbule, O. A., Akujobi, C. N., Ezebialu, I. U., Nduka, A. C., Anahalu, I. C., Okolie, V. E., . . Okor, L. O. (2015). Determinants of post-caesarean wound infection in Nnewi, Nigeria. Journal of Advances in Medicine and Medical Research, 767-774.

Osman, C. (2000). Asepsis and aseptic practices in the operating room. Infect Control Today.

Owolabi, E. (2015). Attitude and practice of nurses towards aseptic technique in the prevention of surgical site infections. African Journal for Physical Health Education, Recreation and Dance, 21(2.2), 257-270.

Zuarez-Easton, S., Zafran, N., Garmi, G., \& Salim, R. (2017). Postcesarean wound infection: prevalence, impact, prevention, and management challenges. International journal of women's health, 9, 81. 